\title{
Liter per Microgram per Kilogram
}

National Cancer Institute

\section{Source}

National Cancer Institute. Liter per Microgram per Kilogram. NCI Thesaurus. Code C120810.

A unit of concentration equal to liter divided by microgram per kilogram. 